\title{
Research on Information Service Mode for University Library in Big Data Era
}

\author{
Di Peng \\ Library, Tianjin Medical University, Tianjin, 300070, China \\ tushu-pengdi@163.com
}

Keywords: big data era; university library; information service mode; innovation strategies

\begin{abstract}
Obtaining useful information from massive data and then feeding useful information back to users, which has become a new trend in the development of library information service in the big data era. University libraries must meet the development trend of big data, integrate information resources of library collections, and establish a brand-new service model based on users' needs and behavioral habits. This thesis, guided by the relevant theories of big data and library science, expounds the connotation and characteristics of big data, analyzes the impact of big data on library information service, and points out the role of big data in the promotion of information service in university libraries, and presents innovation strategies for university library information service model in big data era. The purpose is to improve and innovate university library information service to meet the needs of teaching, research and students' quality training.
\end{abstract}

\section{Introduction}

With the development of mobile internet, social networking, internet of things, and digital office, the speed of information distribution is more convenient, and increase the speed of the number of information accelerating, making the data exponentially increase. These data show the characteristics of large amounts of data, diverse types, low value density, and rapid growth, marking the entry of humans into the era of big data. Data has become an important competitive resource and has become the huge economic asset. Whoever masters data resources will dominate the future. Therefore, the use of big data mining analysis technology deepen mine potential data resources, which is the only way for the development of information technology, and it is also a scientific decision-making process, the inevitable choice. The library is an important place for people to acquire knowledge, and it contains large-scale data. If the resources of the library are fully utilized and information processing is based on advanced methods and ways, the efficiency of data query can be significantly improved and readers can be fully satisfied, and this is also the future development trend of library information service.

The awareness of user information needs in the era of big data has been enhanced, but information selection barriers have made it difficult for users to find information that meets requirements in a variety of data sources. Therefore, libraries are required to provide users with highly targeted and accurate information. Only through data mining, potential valuable information is available. As a basic facility for the inheritance and innovation of human culture, university libraries preserve and disseminate human cultural achievements. It is an important front for the construction of campus culture and an academic institution for collecting, storing, and providing information to promote scientific research activities. In the era of big data, universities libraries must meet the development trend of big data, recognize the situation, seize the opportunity, explore the development and application of big data in university libraries, attach importance to user behavior data, tap potential values in data, and use big data mining. Technology and tools improve and innovate university library information service, provide users with high-level technology platforms, intelligent retrieval, information push and mobile services to meet the needs of university teaching, research and students' quality training. Through this study, on the one hand, promote the innovation and development of library information service, provide methods and experience for 
other types of libraries; on the other hand, promote the further development of university teaching and research, and provide high-quality information service for university teachers and students.

\section{Connotations and Characteristics of Big Data}

Big data refers to the collection of data that cannot be captured, managed, and processed using conventional software tools within the certain time. Big data is considered to be another peak in the information revolution following informationization and the Internet. Big data is about to bring a subversive revolution and will promote overall progress in social production. Big data is not only a large amount of data, but also a way of thinking that "data is king". It not only represents a technical phenomenon, but also carries specific thoughts and methods, and turns into a technical and cultural phenomenon. IBM proposed the $5 \mathrm{~V}$ features of big data:

(1) Volume, data storage jumped from TB level to PB level EB level to ZB level. Up to now, the data volume of all printed materials for human beings is 200PB. IDC's "Universe Report" predicts that global data usage will reach 35 40ZB in 2020;

(2) Velocity, the frequency of generating data and updating is fast, showing the mobility of data flow and big data, and can capture the information of important events first time. This is the most prominent characteristic of big data distinguishing traditional data mining;

(3) Variety, needs to deal with multiple data source, covering different types of text, audio, pictures, video and analog signals, breaking through the traditional structuring category, including semi-structured and unstructured data;

(4) Value, the level of value density is inversely proportional to the total amount of data, the value has scarcity, uncertainty and diversity, and we must make full use of data mining and analysis techniques to find valuable information from massive data;

(5) Veracity, data fraud can be profitable, water injection data leads to soft data softening, the details behind the data, the truth of the data source, and the science of the process, is an important guarantee for big data to be authoritative and credible.

\section{Impact of Large Data to Library Information Service}

With the growing maturity of research and application of big data, libraries are facing increasing pressure. Faced with the pressure of big data, the current library information service are inevitably affected, including the following aspects:

(1) Information service objects are obviously loss. In the past information environment, library information service occupy an important position in the user's information acquisition and information utilization. Users get more information through library information services. In the era of big data, users can get satisfactory information services without leaving their homes and weaken their dependence on libraries. Compared to inefficient library information services with poor timeliness of information and poor service methods, users are more willing to choose convenient, fast-acting, and highly-personalized Internet channels to obtain information, resulting in a significant loss of library users.

(2) Content of information service is not rich enough. The content of information service provided by the library will inevitably require a series of procedures such as collection, processing, production, screening, and procurement. However, the traditional data collection capability is very limited, resulting in the lack of timeliness and limited information content of library information services. Problems such as single forms of information presentation. In the process of information collection, the library may filter out some unreliable data information and reduce the amount of information that the library can provide. Some information that users are interested in can only be obtained through other channels. The library's information resource is very limited compared to the huge data sources on the Internet.

(3) Information service approach is too passive. In the traditional library information service process, users often take the initiative to go to the library to seek information service such as lending and consulting, and the information utilization rate is limited. When receiving service, there 
are often problems such as the fact that the documents have been borrowed, the timeliness of information is poor, and lack of librarians. The extensive use of big data in Internet information service has made library users gradually becoming accustomed to passively accepting service. Without the difficulties encountered in accepting library information service, more and more users will abandon their traditional library information service.

(4) Awareness of information service is relatively backward. In traditional library service, libraries mainly use their own collection resources, librarians, related hardware and software equipment to provide information service to users. They do not place much emphasis on cooperation between libraries, and their clients are only satisfied with local users. Services are one-sided and it is difficult to satisfy users' extensive information needs. In the era of big data, it is necessary to increase the efficiency of library information service, the globalization of information service, and the high level of information service personnel. At present, library information only depends on some readers to develop limited information resources on their own, and there is no effective radiation field through the librarian team.

\section{Promoting Effects of Large Data to Library Information Service in University Library}

In the era of big data, libraries have more targeted and purposeful information service for users, and service tools and service models have also changed with the adjustment of service models. While the university library adjusts the necessary service modes such as subject service, literature service and information consultation, the service features featuring data information processing and service will be further expanded, data analysis, data mining and other information. Service will become the service content of digital libraries in the era of big data. The role of big data in the promotion of information service in university libraries is based on four aspects:

(1) Promote the continuous improvement of university library service technology. The large number of unstructured big data with various types and rapid growth will certainly have a profound impact on the library service that rely on structured data information service. The existing library information data storage and calculation processing technologies are difficult to meet the requirements of big data applications and new knowledge service. The innovation and improvement of library service technology architecture is imperative. Need to design a more reasonable hierarchical storage architecture, the need for high availability of computer data analysis technology; need to support unstructured data analysis and storage of information service facilities.

(2) Promote the continuous improvement of university library service capabilities. The library is no longer a simple document providing and information service, but the use of big data technology to mine the data and knowledge in the literature and information to provide the required data and knowledge for scientific research. Library service will be built on the basis of data analysis and information processing. Big data information space will bring new development opportunities to library services. Through the analysis of complex types of big data, the library captures, mines, and analyzes the knowledge and ideas expressed in unstructured content, thereby providing intellectual support for user decision-making and research innovation.

(3) Promote data information integration service of university library service. Under the trend of big data, the distributed and data structure isomerization of data information systems make large data sources widely dispersed in many different network information nodes. Therefore, the library should use distributed collaborative strategy to integrate various data information, and carefully divide the data information resource space according to various disciplines, so as to build each data information resource subspace, and then target these data information resource subspaces. Correspondingly establishes its data information system, and finally forms the distributed collaborative data information integration system.

(4) Promote cross-border cooperation of university library service. Through cross-border cooperation, we will integrate elements from different fields and infiltrate each other, so as to win more space for the development of the library. Digital resources and bibliographic records are searched on the same platform. The integration of data standards will enable digital resource manufacturers to cooperate with libraries in addition to providing physical resources and taking into 
account digital resource extension service. Cross-border cooperation will be implemented closely. The retrieval system of many university libraries includes the classification and ranking of authoritative reading websites, and analysis of the use of collections under the university's big data structure. As a terminal, readers' activities and reading publicity also require diverse forms and novel contents.

\section{Innovation Strategies on Information Service Mode for University Library in Big Data Era}

In the era of big data, the university library information service model will undergo a fundamental change from a passive service model to an active service model, from a closed service model to an open service model, and from an inward-oriented service model to an outward-oriented service model, from counter-service model to self-service model change. University library information service should adapt to the development trend of big data, adapt and innovate data processing strategies, analyze the compatibility of library technology service, focus on the collection, processing, analysis and mining of data information, and pay attention to the timeliness of information service. Strengthen the integration service of information resources, extensively analyze user information needs, give full play to resource service functions, and enhance individualized service capabilities. At the same time, it is necessary to improve the professional ethics and literacy of the staff. The innovation of university library information service model proposed in this paper in the era of big data includes the following five aspects:

(1) Innovate the idea of information service and change the traditional way of information service. In the era of information service of university libraries in the era of big data, reforms and innovations should be guided by ideas and innovations, and fundamentally implement the service concept of "people-oriented". Libraries under the big data environment must not only refine the knowledge of data and information, but also monitor the entire process of information and information service. The library service model must be continuously reformed and innovated. It should not only pay attention to users' needs of structured information resources, but also focus on collecting, analyzing, and excavating unstructured data of users, and give full play to the role and effectiveness of library big data technology. Rapidly growing demand for big data knowledge users, enhance the digital library's information service capabilities and core competencies.

(2) Pay attention to the core value of big data and forecast user information service requirements. The prediction based on correlation analysis is the core of big data. There is ample evidence that most of human behavior is predictable and subject to laws, models, and principles. In-depth analysis of user data, establishment of user models, precision services and knowledge related services, and provision of predictive information service products; understanding of what happens in the knowledge service process through the data, what service the user needs, and the use of data to interact with the library relationships, data mining, analysis and forecasting of possible information behavior; strengthening of digital resources integration, analysis and mining, identification of high-quality information, and providing information services for customers to solve problems.

(3) Establish WeChat public platform to strengthen communication and contact with users. The WeChat public platform has changed the communication method, convenient and quick information transmission has been accepted by the majority of users. In order to expand the communication channels with users, optimize information presentation methods, and improve user service experience, university libraries can establish public WeChat accounts, pass intimate service, cutting-edge books, and excellent electronic resources to users, and bring libraries and users closer together. Specific service include: regularly promoting and pushing their own service and resources; providing online information consulting service to help users solve various problems in a timely manner; establishing learning mutual help space to help users search for users with common research background or cross-disciplinary background, sharing information resources .

(4) Develop quality evaluation standards and conduct library information service evaluation. The evaluation focuses on the collection of big data, effective data filtering, rapid data processing, cloud computing, and scientific decision-making capabilities. Communication evaluation timely discover the shortcomings of library information service, as well as the problems exist in readers' 
information service, and ensure the quality of library information service. At the same time, through the big data platform and technology, the users' basic information, borrowing habits, reading behaviors and browsing records are analyzed to provide data foundation for library information service evaluation and information service optimization, and reduce library information service risks for users to provide reliable data protection.

(5) Based on development of professional disciplines, continuously expand information service channels. Disciplinary construction is the key to the universites' core competitiveness. The library should embed information service into the front line of teaching and research, and integrate it into discipline construction. Establish and implement the system of subject librarians, strengthen the links between the library and various units, carry out all-round information service and intelligence support, build key information topics, provide excellent resources to users, and help them quickly obtain authoritative information; discipline information service platform, integrate relevant subject network information resources, academic hotspot tracking and evaluation, subject journal submission information, etc., and provide online communication, information exchange and co-construction and sharing to achieve one-stop service of subject resources.

\section{References}

[1] J. Zhong, "The practice and exploration of the cross boundary cooperation of the library," LHebei Library Journal of Science and Technology, vol. 18, no. 5, pp. 17-19, 2015.

[2] Y. D. Liu, "Research on the interactive mechanism of information service in University Library," Journal\%of\%Changchun\%Normal\%University, vol. 37, no. 4, pp. 166-169, 2018.

[3] Victor Chang, Muthu Ramachandran, Gary Wills, et al., "Editorial for FGCS special issue: Big Data in the cloud," Future Generation Computer Systems, vol. 65, no. 12, pp. 73-75, 2016.

[4] Janez Kranjc, Roman Orač, Vid Podpečan, et al., "ClowdFlows: Online workflows for distributed big data mining," Future Generation Computer Systems, vol. 66, no. 3, pp. 38-58, 2017.

[5] Samiya Khan, Xiufeng Liu, Kashish A. Shakil, et al., " A survey on scholarly data: From big data perspective," Information Processing \& Management, vol. 53, no. 4, pp. 923-944, 2017.

[6] Jacky Akoka, Isabelle Comyn-Wattiau, Nabil Laoufi, "Research on Big Data: A systematic mapping study,"Computer Standards \& Interfaces, vol. 54, no. 2, pp. 105-115, 2017.

[7] H. B. He, "Innovation of University Library Information Service Big Data Era," Journal of Modern Information, vol. 34, no. 12, pp. 138-140, 2014.

[8] W. L. Jin, J. Xu, Y. M. Wang, "Information service of university library based on large data," Journal of Wuhan Metallurgical Manager’s Institute, vol. 28, no. 1, pp. 82-83, 2018. 